\title{
O SIGNIFICADO E O SENTIDO DA VIDA HUMANA TÊM ALGUMA IMPORTÂNCIA NA GESTÃO DE PESSOAS?
}

\author{
PROF. JOSÉ A. BONILLA \\ FACE / UFMG \\ E-mail: bonilla.bhz@terra.com.br
}

\section{RESUMO}

Cinco assuntos são abordados neste artigo. O primeiro discute a abordagem holística, que enriquece o cartesianismo prevalecente, através do equilíbrio entre dois princípios, opostos, mas complementares, o auto-afirmativo e o integrativo. 0 segundo, refere-se à Universidade que queremos, ou seja uma organização formatriz e não uma fábrica de profissionais, uma Universidade para a Vida, e não para o sistema econômico. O terceiro, tem a ver com a Vida que queremos. Aqui a alternativa é sermos agentes da transformação social (e pessoal) ou uma safra de clones ao serviço do sistema econômico dominante. O quarto, enfoca a sociedade que queremos, em cujo caso também temos dois caminhos: aprofundar o atual, centrado apenas na riqueza material, ou criar um novo, onde a riqueza esteja constituída pelos grandes princípios universais (dignidade, justiça, solidariedade, bem-estar etc), que serão os grandes objetivos da Vida humana. O quinto, é uma proposta específica para aprofundar o assunto central: o significado da vida humana. Trata-se da formação dos líderes para a Vida.

Palavras-chave: Princípio auto-afirmativo , princípio integrativo, inteligência espiritual, liderança para a Vida.

\begin{abstract}
Five subjects are approached in this article. The first discusse the holistic approach, which enriches the prevalent Cartesianism, through the balance among two opposed, yet complementary, principles: the self-affirmative and the integrative doctrines. The second refers to the kind of University we want, there is, a gestaltian organization, opposed to a factory of professionals - An University that teaches and prepares individuals for life, not for the economical system. The third subject is related to the kind of Life we wish for. The alternatives here are - to act as agents of social (and personal) transformation - or to be a crop of clones to the service of the dominant economical system. The fourth focuses the kind of society we want, in this case we also have two different paths before us: to deepen the current one, merely centered on material wealth, or to create a new path, where wealth is constituted by grand universal principles (dignity, justice, solidarity, well-being etc), which will be the great objectives of human Life. The fifth and last subject refers to a specific proposal to deepen the central subject: the meaning of the human life, and refers to training and preparing individuals to be leaders in Life.
\end{abstract}

Keywords: Self-affirmative principle, integrative principle, spiritual intelligence, leadership in Life. 
Revista Eletrônica de Ciência Administrativa (RECADM) - ISSN 1677-7387

Faculdade Cenecista de Campo Largo - Coordenação do Curso de Administração v. 3, n. 2, nov./2004 - http://revistas.facecla.com.br/index.php/recadm/

\section{INTRODUÇÃO SOBRE ABORDAGEM HOLÍSTICA}

Uma interessante abordagem acerca do Significado da Vida Humana pode ser apresentada através da compreensão holística.

A palavra "holística" vem de "holos" do idioma grego, que significa "totalidade". Ou seja, compreensão holística refere-se a uma compreensão da realidade, em função de totalidades integradas, cujas propriedades não podem ser reduzidas a unidades menores sem perder a essência que as caracteriza. Por exemplo: olhar uma pessoa e perceber seus olhos, seus pés ou a forma que ela sorri, implica num enfoque "analítico". Já ver a pessoa como uma unidade integrada, como um ser humano completo, é ter uma percepção "holística". Enxergar uma empresa como fonte geradora de lucros e em todo caso de empregos, é um enfoque "analítico", portanto parcial. Percebê-la, porém, como um componente do ecossistema social, já é uma percepção "holística". Do mesmo modo, olhar uma floresta e ver nela algumas árvores suficientemente interessantes como para derrubá-las é uma percepção "analítica". Por outro lado, enxergar a floresta como um sistema ecológico equilibrado, integrado por milhares de espécies, é um enfoque "holístico".

Hoje, fala-se muito de novo paradigma, Holística, etc., porém geralmente as informações sobre o assunto são incompletas ou até inadequadas. Entretanto, o significado essencial da abordagem holística, é simples, como apresentado logo a seguir:

O Universo está organizado com base em dois princípios fundamentais: o princípio auto-afirmativo ${ }^{1}$ que privilegia a fração, a parte, a individualidade e a separatividade em todos os sentidos, e o princípio integrativo, centrado no todo, no contexto, no conjunto.

O paradigma prevalecente é o cartesianismo, que está assentado apenas no princípio auto-afirmativo. Sua orientação é reducionista, analítica e mecanicista. Como conseqüência, leva a enxergar o mundo de um modo específico, tingido pelo egoísmo, pelo individualismo e pelas aparências. Seu fruto é a sociedade atual.

- O paradigma holístico sugere um novo modo de ver o mundo, ou seja, um modo de sentir, pensar e agir, alicerçado num equilíbrio entre ambos princípios. Com efeito, a análise e o estudo aprofundado das partes pode fornecer excelentes resultados para o progresso humano, mas se isso é separado do contexto, do conjunto, da Unidade, transforma-se num instrumento poderoso, mas terrivelmente ambíguo, pois também poderão ser obtidos resultados apavorantes. Um deles é a bomba atômica.

- Na prática, o método científico, de natureza cartesiana, pode ser considerado como um instrumento objetivo, capaz de aplicar com elegância, precisão e resultados concretos o princípio auto-afirmativo. Mas é o equilíbrio, através do princípio integrativo, que Ihe fornecerá condições para definir um rumo, uma orientação que seja efetivamente favorável ao bem-estar social.

\footnotetext{
${ }^{1}$ Esses são nomes modernos, para princípios que já eram conhecidos na antigüidade. Por exemplo, há 5.000 anos os chineses falavam de Yang e Yin.
} 
Revista Eletrônica de Ciência Administrativa (RECADM) - ISSN 1677-7387

Faculdade Cenecista de Campo Largo - Coordenação do Curso de Administração v. 3, n. 2, nov./2004 - http://revistas.facecla.com.br/index.php/recadm/

- O enfoque holístico considera que o ser humano está integrado por quatro componentes básicos: físico, mental, emocional e espiritual, sendo que os quatro devem estar perfeitamente equilibrados para poder desenvolver uma vida individual sadia e feliz, no meio de uma sociedade humana digna e justa.

- O enfoque holístico não rejeita o cartesiano e sim o enriquece. Quando surge algum problema importante, em lugar de fracioná-lo imediatamente, ele é expandido, visando entender o contexto. Depois que este é percebido, podemos voltar à "parte" ou fragmento.

- A palavra "Holismo" ou "Holística" foi usada por primeira vez em 1926, mas só a partir de 1980 é que começa a ser difundida com certa amplitude.

A abordagem holística implica - antes de tudo - em uma nova percepção acerca das coisas, uma forma nova de sentir, de pensar e de agir. Ele considera o homem como um "holon", portanto como uma totalidade, como uma unidade e sabe-se que nessa unidade existem vários níveis: físico, emocional, intelectual e espiritual. Isto significa basicamente duas coisas: em primeiro lugar, o enfoque holístico não tem a pretensão de substituir o método científico, mas sim de enriquecê-lo através de uma síntese entre ambos (o método científico-holístico é por enquanto um embrião, mas é o principal trabalho a ser desenvolvido e completado pelos mais competentes epistemólogos do século XXI); em segundo lugar, o holismo pretende substituir o racionalismo falso, o "racionalismo" irracional que prima em nossa sociedade.

Diz-se que nossa sociedade está baseada na racionalidade. Mas isto não é verdade, pelo que precisamos rejeitar essa afirmativa. Para falar com precisão, podemos dizer que esta sociedade está governada pela macro-irracionalidade, possuindo algumas ilhas de micro-racionalidade. Por exemplo, o método para fabricar um certo produto industrial pode ser racional no relativo ao aproveitamento ótimo das matérias-primas disponíveis (seria uma boa demonstração de microracionalidade). Mas a devastação, destruição e poluição que subjazem ao método específico, assim como o uso do produto, muitas vezes supérfluo, desnecessário ou até absurdo ou daninho para a Humanidade, são demonstrações claras da macroirracionalidade.

O enfoque holístico procura a racionalidade integral, a qual para se mostrar em toda sua plenitude, precisa dos outros níveis do ser humano, especialmente do emocional e do espiritual. O enfoque holístico não se contenta apenas em saber como fazer as coisas (para lucrar mais); sua preocupação maior é com: por que fazer? para que fazer? para quem fazer?

E qual será a relação entre abordagem holística e significado da vida humana? Antes de tudo, deve ser compreendido que a Holística conduz a uma nova visão de mundo e de nós mesmos, de natureza transdisciplinar. Em lugar de ficarmos presos às experiências materiais e ao raciocínio (princípio autoafirmativo), vamos a beber nas frescas águas da afetividade e da espiritualidade (princípio integrativo).

A Ciência mais avançada, a Física quântica, já quebrou os paradigmas que ainda amarram outras à tridimensionalidade. Especialmente as Ciências Administrativas e as Econômicas, como hipnotizadas pelo dinheiro que é, 
evidentemente, um bem físico, estão entre as mais atrasadas em relação ao novo paradigma holístico.

É fato, entretanto, que os caminhos da Ciência mais avançada e os da Espiritualidade genuina, se mostram mais e mais convergentes (ver, por exemplo, Capra, 1982). Por isso, os físicos sub-atômicos, os maiores como Einstein e Bohr, perceberam claramente a necessidade de se aplicar ao estudo do misticismo autêntico (absolutamente diferente da charlatanice exposta diariamente na televisão ou por grupos pseudo-religiosos).

O princípio integrativo, expressão que não deve ter mais de trinta anos, e que representa o caminho que a Humanidade precisará percorrer para sair do pântano em que se encontra, é um conceito novo na forma, mas não na sua essência. O principal divulgador desse princípio em todos os tempos, foi Jesus $O$ Cristo, só que Ele utilizou uma palavra muito singela em lugar das modernas. Uma simples palavra de quatro letras (Amor), lamentavelmente hoje deturpada, comercializada e ironizada.

O significado da vida humana, através da abordagem holística, pode ser entendida como o equilíbrio entre os dois princípios básicos (auto-afirmativo e integrativo) e entre os quatros componentes do ser humano (material, mental, emocional e espiritual).

Esse equilíbrio só pode ser encontrado, tomando como alicerce indestrutível o componente mais sutil, que é o espiritual. Nessa abordagem, fica claro que o objetivo, o significado da vida humana é a harmonização do terreno, de baixa freqüência vibratória, com as altas freqüências vibratórias do mundo superior. Ou seja, o homem sendo possuidor de ambos atributos, é o intermediário entre a matéria física e o mundo espiritual, através de seus pensamentos e sentimentos (elevados).

É essa uma nova forma de ver, de sentir e de compreender as coisas, e sobretudo de agir em consonância com ela.

\section{QUE UNIVERSIDADE QUEREMOS?}

Há consciência crescente de que a revolução técnica-científica já não dá mais conta dos problemas da Humanidade. A Unesco (1998) o definiu com clareza: "A Educação Superior deve empreender a transformação e renovação mais radicais que jamais tenham enfrentado, de forma que a sociedade contemporânea, que vive atualmente uma crise profunda de valores, possa transcender as considerações meramente econômicas e assuma dimensões éticas e espirituais mais arraigadas".

A Universidade é uma estrutura integrada de Ensino, Pesquisa e Extensão. Mas por quê? para quê? para quem, deve servir essa estrutura? Para o sistema econômico em primeiro lugar, ou para a sociedade tomada como conjunto? Segundo um enfoque cartesiano, que beneficia uns poucos e sacrifica muitos, ou segundo um enfoque renovador (holístico), que se fundamenta no auto-desenvolvimento, na auto-consciência e na responsabilidade social? 
Revista Eletrônica de Ciência Administrativa (RECADM) - ISSN 1677-7387

Faculdade Cenecista de Campo Largo - Coordenação do Curso de Administração v. 3, n. 2, nov./2004 - http://revistas.facecla.com.br/index.php/recadm/

Que Universidade queremos? Aquela que hoje prevalece e se assemelha mais a uma fábrica de profissionais, ou queremos uma organização formatriz, que forma cidadãos, que simultaneamente, dominam um campo de conhecimento, por exemplo Administração?

Se quisermos optar pelo segundo tipo, é necessário impulsionar a renovação profunda que apregoa a Unesco, capaz de transformaras estruturas universitárias, de modo que elas substituam sua atual obsolescência, por formas compatíveis com um desenvolvimento acelerado, mas centrado no ser humano, e não no sistema imperante.

Precisamos criar a Universidade para a vida, e abandonar a Universidade para o sistema (econômico).

Portanto é válido o enfoque de Ribeiro (1969) quando propõe que a Universidade Latinoamericana deve transformar-se em algo que esteja o mais cerca possível do que ele chama a "Universidade criadora", ou seja: "o órgão através do qual, a sociedade nacional se capacita instrumentalmente para dominar, cultivar, aplicar e difundir o patrimônio do saber humano e cuja responsabilidade educativa não pode reduzir-se ao âmbito do ensino informativo e da especialização profissional, exigindo um zelo especial para oferecer à juventude, oportunidades de: maturidade intelectual como herdeiro do patrimônio cultural humano e formação cívico-ideológica visando fazê-los cidadãos responsáveis de seu povo e de seu tempo".

A isso, seria necessário acrescentar que aquele domínio, cultivo, aplicação e difusão do saber humano, deverá ser orientado em forma construtiva, procurando um aumento da qualidade de vida da espécie humana e não dirigi-lo - como agora - de forma aparentemente "objetiva" mas que tem servido - basicamente - para aumentar a distância existente entre as classes sociais e entre as nações. Por outro lado, é muito bom que os jovens tenham maturidade intelectual e formação cívicoideólogica, mas também é imprescindível estimulá-los a ter uma visão integral, holística do mundo, e da natureza das interrelações nele contidas; a compreender que cada um de nós é também uma Unidade, e que não podemos separar - em todos os níveis - o que é racional do que é emocional, e do que é espiritual; a sentir o Universo como uma magnífica manifestação de um grande substrato trans-físico que o sustenta, como a própria Física subatômica já o demonstrou.

Em resumo, o que proclamamos como necessário é o reconhecimento que os aspectos éticos, sociais e ambientais, devem prevalecer sobre os grosseiros objetivos atuais, estampados a fogo no seio da sociedade moderna: status, poder, domínio sobre os outros, impunidade, corrupção e consumismo.

Ou seja, a Universidade criadora deveria incorporar - para possibilitar o desenvolvimento de si mesma em forma plena, harmônica e auto-realizada, e sua posterior expansão à comunidade que a mantém - de uma forma ou de outra - uma verdadeira dimensão holística. Nesse caso, fará justiça e honra a seu próprio nome: Universidade.

Em nosso entender, os objetivos básicos de formação de um profissional universitário, em forma muito resumida, são os seguintes: 
Revista Eletrônica de Ciência Administrativa (RECADM) - ISSN 1677-7387

Faculdade Cenecista de Campo Largo - Coordenação do Curso de Administração v. 3, n. 2, nov./2004 - http://revistas.facecla.com.br/index.php/recadm/

\section{a) Objetivos técnico-científicos}

- Preparação adequada de profissionais, capacitados para se desempenharem satisfatoriamente no ensino superior e médio, assim como em projetos de pesquisa científica ou tecnológica.

- Preparação de profissionais capazes de desenvolver de forma satisfatória, atividades em organismos assessores e planejadores do setor público correspondente.

- Preparação de profissionais que possam se encarregar de planejar, dirigir e executar tarefas relativas a sua formação, no âmbito da atividade privada.

\section{b) Objetivos éticos- sociais}

- Preparar cidadãos que estejam informados dos grandes problemas de seu tempo e que - portanto - sejam capazes de analisar criteriosamente as diversas e complexas situações que devem ser enfrentadas constantemente em nossa sofisticada sociedade moderna.

- Preparar cidadãos que estejam capacitados para conhecer o significado, o conteúdo e os limites da ciência e da tecnologia, e sua relação com o renovado sonho da espécie humana de paz, fraternidade, igualdade, liberdade e justiça.

- Preparar cidadãos que desenvolvam um sentido ético a partir de critérios de validade social e autêntica espiritualidade (e não em base a dogma herdados de deturpação dos ensinamentos originais ou engendrados em nossa atual sociedade de consumo).

- Preparar cidadãos dotados de compreensão holística e ecológica, capazes de perceberem o Universo, o planeta e a Natureza como uma Unidade, onde nós, seres humanos, não tecemos a rede da vida. Em troca, somos apenas um fio dela. Desta forma, o princípio integrativo, tão escasso hoje em dia, poderá equilibrar-se com seu oposto complementar, o princípio auto-afirmativo.

Ou seja, a Universidade deveria formar um profissional que tenha, simultaneamente: sólida base técnico-científica; um alto grau de sensibilidade ética, social e ambiental; e uma abordagem holística dos grandes assuntos de Humanidade aplicados às necessidades sociais específicas. Essa é a Universidade que queremos. Na atualidade - via de regra - se está bastante longe desta proposta, que para alguns - talvez para muitos - tem característica de utopia.

Hoje em dia existem basicamente duas tendências opostas na Universidade Latinoamericana. Uma delas considera a Universidade como a instituição mais "avançada" da sociedade, cuja principal razão de ser reside no fato de que ela é o "mecanismo" fornecedor de profissionais e técnicos que essa sociedade (ou melhor: certos grupos dessa sociedade) necessitam. E quanto mais eficiente seja na tarefa de prepará-los para essas incumbências, qualitativas e quantitativamente, mais será reconhecida cada Universidade especifica. 
Revista Eletrônica de Ciência Administrativa (RECADM) - ISSN 1677-7387

Faculdade Cenecista de Campo Largo - Coordenação do Curso de Administração v. 3, n. 2, nov./2004 - http://revistas.facecla.com.br/index.php/recadm/

A grande jogada dessa tendência é identificar as necessidades de sociedade tal está organizada, com as necessidades reais da mesma. A diferença entre ambas, pode ser fantástica. No bojo da globalização contemporânea, essa tendência prevalece, considerando qualquer outra alternativa um mero lirismo.

Mas existe outra tendência, ainda incipiente, que considera a Universidade como a instituição mais "esclarecida" da sociedade, e por este motivo portadora da irrenunciável responsabilidade moral, não de "produzir" os profissionais que o setor dominante da sociedade necessita, e sim examinar a natureza e o comportamento dos diferentes segmentos dessa comunidade, questionar os aspectos para o conjunto, que alguns deles representam e propor as correspondentes soluções. Ou seja não se trataria de uma Universidade apagada, mero reflexo "aculturado" da sociedade que a rodeia. Em lugar disso, ela seria um "dinâmico agente de mudanças". Nesse sentido, a Universidade teria a responsabilidade de formar (e deve-se enfatizar o uso do verbo "formar" em vez de "produzir") aqueles profissionais que ela entenda devam responder às necessidades atuais (e futuras) dessa sociedade.

Essas necessidades, se relacionam com as mudanças quali-qualitativas básicas de estrutura sócio-econômica e das relações entre os seres humanos, e não apenas aquelas que sirvam para preencher as necessidades sentidas por alguns setores dessa sociedade que são - "casualmente" - em forma preferencial, os grupos mais poderosos desde um ponto de vista econômico.

\section{Acreditamos que, embora a tarefa seja hercúlea, essa é a Universidade que queremos.}

\section{QUE VIDA QUEREMOS?}

Empresários, profissionais, professores, estudantes, trabalhadores e o resto da população temos algo em comum: somos seres humanos. Mas que vida queremos? Queremos ser agentes de transformação social ou ser mais uma safra de clones, que respondem automaticamente aos interesses do sistema econômico dominante?

Qual é o recurso que nos pode ajudar? Zohar e Mansell (2000), apresentam a importância da autoconsciência nesse processo, assim como o estado atual de seu desenvolvimento na atual sociedade globalizada: "A autoconsciência é um dos critérios mais importantes da inteligência espiritual elevada, mas também uma das prioridades mais baixas da cultura espiritualmente embotada em que vivemos. Desde os primeiros dias na escola, somos treinados a olhar para fora, e não para dentro"..."Virtualmente, nenhuma coisa, na educação ocidental nos encoraja a refletir sobre nós mesmos, nossa vida interior, nossos motivos. Ninguém nos estimula a dar assas à imaginação".

Mas o que seria "espiritual"? Fé religiosa? Visão aérea? Charlatanice? Boff (2000) diz: "Espiritualidade é aquilo que produz uma mudança interior, uma transformação em nós".

Como conseqüência desse estado de coisas, para atingir essa transformação, é mister uma mudança total nas estruturas básicas em que se apoia o pensar, o 
Revista Eletrônica de Ciência Administrativa (RECADM) - ISSN 1677-7387

Faculdade Cenecista de Campo Largo - Coordenação do Curso de Administração v. 3, n. 2, nov./2004 - http://revistas.facecla.com.br/index.php/recadm/

sentir e o agir. É impossível essa tarefa? Se lermos um pouco de História, percebemos que não. Por exemplo, nas trevas medievais predominava o pseudoespiritualismo da Santa Inquisição, aliada com o poder físico da nobreza. Entretanto, o espirito humano não suportava mais essa prisão; é nesse contexto que surge o racionalismo, que era outro modo de pensar, sentir e agir.

Hoje o racionalismo, que já deu um bom serviço à Humanidade, é insuficiente para abordar com amplitude a atual problemática planetária. Portanto, o espirito humano - necessariamente - quebrará os grilhões em procura de vôos mais altos, representados atualmente pela abordagem holística.

Da mesma forma que no Renascimento, a renovação se produziu através do racionalismo e da liberdade artística, no século XXI ela ocorrerá, apoiada na convergência entre a Ciência mais avançada e a espiritualidade milenar, aliança que começou a se desenvolver rapidamente nos últimos 30 ou 40 anos.

Nesse contexto, deve-se lembrar um conceito espiritual básico: tudo o que precisamos está dentro de nós. Ou seja, não precisamos nos tornar alguma coisa: empresários bem sucedidos, trabalhadores satisfeitos ou professores destacados. Mas para encontrar dentro de nós esse "todo", temos que reconhecer e aprimorar-nos na disciplina mais abrangente que existe: o desenvolvimento espiritual. E quando o incorporemos aos estudos universitários, não estaremos entrando num inconseqüente sonho aéreo, e sim, apenas seguindo as recomendações da organização educacional mais importante do mundo: a Unesco.

Hoje, a discussão nas aulas universitárias, em grande parte exacerbadamente racionalista, não aborda o significado da vida humana (Bem que gostaríamos conhecer alguma Escola onde esse assunto fosse tratado com profundidade!). Com certeza, o motivo principal desse "esquecimento" é que, logo de cara, seria necessário abordar a espiritualidade!

Não temos espaço aqui para discutir as pesquisas científicas realizadas nas grandes Universidades, comprovando experimentalmente a existência da inteligência espiritual (Wolman, 2001; Zohar e Marshall, 2000, entre outros).

Esses autores - e outros - separam claramente espiritualidade de religiosidade. Zohar e Marshall (2000) definem "inteligência espiritual como a inteligência com que abordamos e solucionamos problemas de sentido e de valor"... "Seres humanos são, essencialmente, criaturas espirituais, porque somos impulsionados pela necessidade de fazer perguntas "fundamentais" ou "finais", tipo: qual é o significado de minha vida? O quê a torna digna de ser vivida?".

Wolman (2001) a define como: "a capacidade humana de fazer as perguntas fundamentais sobre o significado da vida, e de experimentar, simultaneamente, uma conexão perfeita entre cada um de nós e o mundo em que vivemos"... "É um conceito abrangente, do qual as religiões são subsistemas".

Dillard (1999) acrescenta: "A espiritualidade fala à necessidade mais fundamental de todas: a necessidade de saber que, de algum modo, somos importantes, que nossas vidas significam alguma coisa, que contam como algo mais que um simples lampejo momentâneo do Universo". 
Revista Eletrônica de Ciência Administrativa (RECADM) - ISSN 1677-7387

Faculdade Cenecista de Campo Largo - Coordenação do Curso de Administração v. 3, n. 2, nov./2004 - http://revistas.facecla.com.br/index.php/recadm/

E nós perguntamos: existe para um ser humano não petrificado, algo mais importante que tentar respostas para tão abrangente assunto? E se não o discutirmos nas Universidades, que representam o cúmulo do conhecimento universal através de todos os tempos, onde poderíamos trocar idéias? O devemos deixar que auto-nomeados representantes de Deus as interpretem e as apresentem prontinhas para engolir, como pílulas manipuladas?

Só para arredondar esse assunto, apresentaremos um novo excerto de Zohar e Marshall (2000): A inteligência espiritual tem sido tópico embaraçoso para acadêmicos, porque a ciência atual não está preparada para estudar coisas que não possa medir objetivamente"... "Mas, existe de fato, um grande volume de provas científicas da inteligência espiritual em estudos psicológicos, neurológicos e antropológicos recentes, da inteligência humana, e em estudos sobre pensamento humano e processos lingüísticos. Cientistas já realizaram a maior parte da pesquisa básica que revela as fundações neurais da inteligência espiritual no cérebro".

Por sua vez Hawley (1995) afirma: "Espírito tem a ver com fome de objetivo, significado e identidade. Temos fome de um contato mais rico com a Vida; ansiamos pela experiência de uma "Vida" plena, vibrante, enquanto nos encontramos neste planeta. Temos fome de compreender quem somos e como nos encaixamos neste todo. É como se todo o tempo que passamos sem respostas, tivesse feito com que a fome crescesse".

$\mathrm{E}$ aqui voltamos para o passado. $\mathrm{O}$ futuro não pode ser grandioso e nem sequer digno, se esquecermos o que os homens mais desenvolvidos nos têm ensinado. Até o iconoclasta Nietszche reconhece a prevalência do espírito. E lá estão Jesus, Buda, Paulo, Platão, Hermes Trismesgisto, Aquenaton e os modernos Luther King, Gandhi, Madre Tereza e o Dalai Lama.

Que feitiço feito pelos adoradores do bezerro de ouro, pode - no Terceiro Milênio - continuar adormecendo as consciências humanas e deslumbrá-las como crianças, cujos olhos brilham com papel pintado e brinquedos dinâmicos?

Assagioli (1971) define o drama central da Humanidade como a "necessidade da fusão de nossa personalidade com nosso Eu Interior". Mas isso é, em todo caso, uma redescoberta, pois há milênios, os sábios reunidos em locais inexpugnáveis como as Pirâmides, conheciam esse fato como o credo básico de todas as escolas misticas e de qualquer religião. Entretanto, algumas destas, penetradas pela ambição e pela ignorância, e apenas vestindo máscaras de espiritualidade sob um corpo afundado na pseudoespiritualidade, através de assalto às posições de poder, como foi o caso de Torquemada, levaram a pessoas lúcidas (entre elas Marx: "a religião é o ópio dos povos"), a descrer de tudo o que não podem perceber com seus recursos sensoriais.

Em resumo: que Vida queremos? Acreditamos que seja uma vida palpitante, cheia de luz, solidária, frugal e harmoniosa. O Criador que paira acima de todas as religiões, nos dará essa Vida de presente, talvez em Natal, como se fosse um bondoso Papai Noel?

Negativo. Essa Vida Plena deverá crescer a partir das sementes que cada um de nós semeará todos os dias, a despeito que muitas sejam dispersas pelo vento, 
Revista Eletrônica de Ciência Administrativa (RECADM) - ISSN 1677-7387 Faculdade Cenecista de Campo Largo - Coordenação do Curso de Administração v. 3, n. 2, nov./2004 - http://revistas.facecla.com.br/index.php/recadm/

afundadas nas águas, comidas pelos passarinhos, calcinadas pelo sol ou extraviadas entre os espinhos... sempre haverá algumas que cairão em terra fértil... e cada uma delas, frutificará em mil grãos, que continuarão o Ciclo Cósmico. 
Revista Eletrônica de Ciência Administrativa (RECADM) - ISSN 1677-7387

Faculdade Cenecista de Campo Largo - Coordenação do Curso de Administração v. 3, n. 2, nov./2004 - http://revistas.facecla.com.br/index.php/recadm/

\section{QUE SOCIEDADE QUEREMOS?}

Há duas formas de abordar o problema da sociedade humana. Uma, superficial, é o enfoque prevalecente: parecemos estar numa corrida, onde apenas temos que correr (não se sabe para onde, talvez para o abismo!) e cada vitória será recompensada até fartamente com recursos materiais.

A outra abordagem é bem mais profunda, envolvendo a "Nova" Realidade, proposta pela Física (relatividade, teoria quântica, teoria da complexidade), que na verdade, apenas coloca em linguagem moderno e operacional, os conhecimentos dos sábios antigos. Essa "Nova" Realidade conduz a idéias cada vez mais surpreendentes. Elas nos dizem que existem evidências de que nosso mundo e tudo que ele existe - um elétron, uma partícula de pó, uma flor, um ser humano e até uma galáxia - são projeções provenientes de um nível de realidades, praticamente fora do alcance do tempo e do espaço.

$\mathrm{E}$ quem disse isso? Visionários, sonhadores, poetas, taumaturgos ou alucinados? Os que colocam essas idéias estonteantes, são does dos maiores cientistas da década de 90: David Bohm, físico, Professor da Universidade de Londres, e protegido de Einstein, e Karl Pribram, famoso neurofisiologista , Professor da Universidade de Stanford. Eles chegaram àqueles conclusões, partindo de origens deferentes e percorrendo estradas diversas.

Dito em outras palavras, as teorias cientificas mais avançadas, atribuem ao Universo a propriedade de ser uma espécie de holograma gigante. Mas uma vez, e agora de forma cientificamente convincente, se nos oferecer uma visão das coisas tipicamente holística: energia subjacente e manifestação.

Manifestação é o que percebemos sensorialmente; energia subjacente, é o que confere existência àquela. A manifestação envolve matéria e mente; a energia subjacente, afetividade e espiritualidade.

Entretanto, em Ocidente se está, basicamente, preocupado com as manifestações, representadas pelo princípio auto-afirmativo, que quando cresce excessivamente, se transforma numa praga, de modo que o necessário crescimento pessoal, se transforma em inchação (de riqueza material). Por sua vez desprezamos, desconsideramos ou ignoramos a subjacência, representada pelo princípio integrativo.

Os místicos antigos - de todos os povos - conheciam bem esses fatos, não através da experimentação científica, e sim da meditação e outras artes. Como disse Hawley (1995), volta a se tornar vital "a agenda do espírito".

O Universo seria um holograma ... Mas o que é, a final um holograma? Trata-se de um conceito que pode ser compreendido intuitivamente sem muita dificuldade, mas que intelectualmente se apresenta complexo.

Holograma seria um tecido continuo que tem diversos níveis (ou "ordens implícitas" segundo Bohm). Ou seja, o Universo é uma teia única, e tudo o que existe é parte dessa continuidade. Portanto, não existe separação ou independência entre os elementos; a individualidade humana, tão cara à filosofia de vida americana, acontece só a um certo nível (princípio auto-afirmativo); mas num nível cada vez mais profundo (princípio integrativo), somos parte do Todo, do Universo. Para 
Revista Eletrônica de Ciência Administrativa (RECADM) - ISSN 1677-7387

Faculdade Cenecista de Campo Largo - Coordenação do Curso de Administração v. 3, n. 2, nov./2004 - http://revistas.facecla.com.br/index.php/recadm/

restabelecer essa compreensão, que é essencial se realmente desejamos melhorar a sociedade atual, devemos utilizar todos os recursos necessários. É por isso que a dimensão espiritual deve ser introduzida na Educação.

Por exemplo, diz Talbot (1991) "acreditamos que podemos lidar com vários problemas em nossa sociedade, tais como crime, pobreza e drogas, sem considerálos como um todo e assim por diante". Para superar esta grande limitação, precisase abordar em forma holística, o Universo, a Natureza, a Humanidade, cada ser humano etc.

A característica mais notável de um holograma é que mesmo um fragmento muito pequeno dele pode reconstruir a totalidade! Ou seja, dentro de cada parte está incluído o Todo!

Mas que totalidade é essa? Sabetti (1991) diz:

"Está acontecendo uma silenciosa revolução que afeta nossos padrões de vida e nossa compreensão sobre o funcionamento do Universo"..."Trata-se de uma mudança sutil, embora radical, que penetra todos os segredos da vida moderna. Esta revolução é a redescoberta do senso de totalidade" ... "Essa totalidade, tem sido esquecida com demasiada freqüência num mundo de objetivos lineares e de produção rápida ${ }^{2}$. No entanto, aos poucos, estamos começando a redescobrir que todas as expressões humanas - na atmosfera, no lar e no de trabalho - são círculos de energias que, em última análise retornam a nós. Esta é a revolução: um retorno à natureza da totalidade, que é a essência do nosso Universo como um Todo".

\section{Esta afirmação envolve a dimensão espiritual.}

Acrescenta Sabetti (1991): "a totalidade é um campo vibratório que traz ordem, harmonia e integração à vida, através da energia vital, trata-se do princípio básico do Universo. Manifesta-se no corpo como saúde, no plano emocional como amor, e no plano espiritual como a alma".

E nos negócios, dizemos nós, a totalidade se manifesta a nível humano como ética, a nível planetário como responsabilidade ambiental, e a nível universal, como espiritualidade. Trata-se de uma verdadeira trindade, cuja subjacência é a totalidade. Entretanto, no mundo dos negócios o que hoje prevalece é uma visão fragmentada, individualista, utilitarista e imediatista. Trata-se do medo à totalidade ou holofobia. Ele também se desenvolve no meio universitário. Os antídotos a esse medo são precisamente a responsabilidade social, a ética e sobretudo um nível mínimo de compreensão espiritual. A força que permeia os diferentes níveis de Universo, impregna todas as coisas e as faz movimentarem-se, chama-se energia vital.

Essa energia vital, não estudada em nossas Universidades, já era conhecida pelos antigos egípcios (ka); chineses (ri); indianos (prana); tibetanos (lung); hebreus (ruach); etc. Goethe chamou-a de "gestaltung", Bergson de "élan vital" e Koestler de ... princípio integrativo (em 1967). E como já vimos, esse princípio está composto pelas dimensões afetiva e espiritual.

Retomando uma abordagem cientifica, Guitton e Bogdanor (1991) nos dizem:

\footnotetext{
${ }^{2}$ Ou seja, os alicerces do sistema, “adorado” por alguns, do “management” americano.
} 
Revista Eletrônica de Ciência Administrativa (RECADM) - ISSN 1677-7387 Faculdade Cenecista de Campo Largo - Coordenação do Curso de Administração v. 3, n. 2, nov./2004 - http://revistas.facecla.com.br/index.php/recadm/

"Num Universo submetido à entropia irresistivelmente arrastado para uma desordem crescente, por que e como aparece a ordem?"..."Abre-se uma nova cosmologia, um modo profundamente de pensar a própria realidade: por trás da ordem evanescente dos fenômeno, a Física Quântica toca de modo surpreendente a Transcendência ${ }^{3}$... até roçar o mais fundamental enigma que desafia o espírito humano: a existência de um Ser Transcendente, ao mesmo tempo causa e significação do grande Universo".

É fato que as ciências mais avançadas e a sabedoria tradicional (espiritualidade) coincidem em que o limite entre o "material" e o "espiritual" é arbitrário. Trata-se apenas de diferentes níveis de energia. Tudo o que existe, em qualquer plano, tem a sua especial freqüência vibratória. As mais baixas (desde o tato, até 16 vibrações por segundo, o som, de 16 a 16.000 ... até raios gamma e raios cósmicos, com vibrações da ordem $10^{20}$ até $10^{25}$ por segundo) já foram detectadas, estudadas e aplicadas através dos recursos próprios do método cientifico. As mais altas, até agora, são de domínio exclusivamente espiritual. É bom lembrar que por, exemplo, as ondas de rádio (com $10^{4}$ até $10^{10}$ vibrações por segundo) existem desde tempos imemoriais, mas para os cientistas de um século atrás, não existiam! (Marconi, quase foi internado em um hospício por seus "amigos" quando anunciou a existência dessas ondas, hoje chamadas hertzianas; evidentemente Hertz teve mais sorte e compreensão).

As freqüências espirituais devem vibrar acima de $10^{25}$ por segundo, pelo que escapam à mensuração cientifica com a instrumentação atualmente disponível. Mas elas são compreensíveis a níveis vivenciais: as sentimos (a menos que estejamos petrificados) sem poder explicá-las.

Essa petrificação parece muito estendida nos meios acadêmicos ${ }^{4}$, Entretanto, a integração da ciência com a tradição espiritual (sabedoria milenar), fornecerá uma formidável via para a expansão da compreensão de coisas simples, mas até agora não respondidas pela Ciência, e nunca discutidas na Universidade. Por exemplo, para que estamos aqui? Ou seja, qual é o significado da Vida Humana?

É fundamental sim, conhecer o mundo físico (eis o grande papel da Ciência). Mas isso é apenas um meio para o fim fundamental: conhecer o ser humano e transformar a sociedade num lugar melhor para viver, onde valores universais (dignidade, justiça, solidariedade, bem-estar, etc.) sejam os grandes objetivos da vida. E não podemos fazer isso sem nos envolver com a dimensão espiritual (que, não está demais esclarecer é bem diferente de religiosidade). Essa é a sociedade que queremos.

Portanto, dando mais força ao coração e à alma sem esquecer a necessária atividade física e mental, precisamos formar nas Universidades, profissionais diferenciais que serão a massa critica capaz de catalisar a reformulação de nossa sociedade. A missão a cumprir será a de que essa sociedade possa servir para satisfazer as autênticas necessidades humanas, substituindo a "realidade atual", onde as pessoas são utilizadas para satisfazer as necessidades dos grupos de poder.

\footnotetext{
${ }^{3}$ Ou seja, a dimensão espiritual.

${ }^{4}$ Assim como nos políticos, econômicos etc.
} 
Revista Eletrônica de Ciência Administrativa (RECADM) - ISSN 1677-7387

Faculdade Cenecista de Campo Largo - Coordenação do Curso de Administração v. 3, n. 2, nov./2004 - http://revistas.facecla.com.br/index.php/recadm/

\section{UMA PROPOSTA ESPECÍFICA: A FORMAÇÃO DE LÍDER PARA A VIDA}

As Universidades e Centros Universitários públicos e privados, os centros de pesquisas e as empresas consultoras, em sua ampla maioria, formam ou desenvolvem líderes com conhecimentos técnico-científicos bem aprofundados.

A pergunta básica, entretanto, é: líderes para quê?. Apenas para processar a geração de lucros?, ou também e sobretudo, para a Vida?

Numa Escola de Administração, por exemplo, o aluno cursa disciplinas relativas às teorias da Administração, às áreas de apoio tais como Estatística, Informática, Metodologia de Pesquisas ou Elaboração de Projetos, assim como aquelas relacionadas com a sua aplicação profissional, tais como Recursos Humanos, Marketing, Finanças ou Produção.

Tudo isto é necessário. Mas este enfoque está perigosamente orientado apenas para o mercado. Como lucrar mais é o grande (e único) objetivo.

Precisamos, é claro, ter profissionais competentes para se inserir na sociedade atual e possibilitar sua sobrevivência e sua prosperidade. Entretanto, a grande pergunta que atualmente se apresenta como exclusiva é: como fazer? Ela precisa ser ampliada para: por quê fazer?, para quem fazer?

Um novo ingrediente então entra em jogo: a Vida humana. Para que vivemos? Apenas para sermos parafusos de um sistema, e poder assim mergulhar na ciranda de um consumismo doentio que hoje nos asfixia? Ou a missão do ser humano será mais abrangente? Por exemplo: desenvolver nossas potencialidades internas, ou seja os atributos que nos foram doados pelo Criador, para fazer da atual uma sociedade melhor?

Quais os ideais que passaremos para as futuras gerações?. Ou escolheremos contribuir com nosso grão de areia para produzir mais gerações fracassadas?

Num momento em que a sociedade humana se encontra impregnada por um materialismo feroz e asfixiante, saturada de violência, de corrupção, de fome e de consumismo, de destruição ambiental, de luxo e de lixo, precisamos reagir.

$E$ esta reação começa pela necessidade de formar pessoas que se transformem em líderes para a Vida, substituindo a atual tendência que cada vez mais sofistica os conhecimentos para fazer progredir os lucros à custas de um sacrifício maior do meio ambiente e das próprias pessoas.

O que seria um líder para a Vida? Seria um cidadão que tivesse recebido formação suficiente para compreender que o mundo exterior pode ser mudado a favor do ser humano, se descobrirmos primeiro a riqueza de nosso mundo interior, para depois fazer a síntese entre eles através de um Projeto de Vida Pessoal que seja, simultaneamente bom para ele e bom para a sociedade.

Precisamos professores, pesquisadores, profissionais de todas as áreas, líderes comunitários e sindicais, estudantes avançados etc, para se transformarem em multiplicadores desta idéia. 
A sociedade humana já atravessou a penosa fase da sensibilização e está entrando de cheio na de conscientização. É agora necessário dar o salto qualitativo: agir. Mas precisamos agir não apenas rearranjando o mundo exterior e deixando o mundo interior como está. A História humana, especialmente do século XX mostrou que isso não resolve a problemática básica da Humanidade: compreender qual é a nossa missão cósmica e cumpri-la.

Até agora acreditamos que mudando pela força (ou pela lei) as instituições políticas, sociais e econômicas poder-se-ia trazer felicidade para os povos. Entretanto, as dolorosas experiências de guerras inúteis e revoluções fracassadas mostram claramente que não podemos trabalhar apenas com a mente e sim que devemos colocar em jogo o coração e a alma.

Isto é formação de líderes para a Vida. E essa formação é - parece-nos - a principal responsabilidade que no início do século XXI devem desenvolver as instituições que mereçam realmente o nome de educativas e não meramente fornecedoras de instrução (e portanto, apenas fabricantes de profissionais). 


\section{* Objetivo geral}

Formar uma massa crítica suficiente de pessoas na sociedade brasileira, visando a sua conscientização e ao desenvolvimento das correspondentes ações em prol do resgate dos autênticos valores humanos.

\section{* Objetivos específicos}

- Contribuir para a preparação de cidadãos que tenham capacidade de percepção suficiente como para analisar com discernimento as diversas e complexas situações da vida moderna, a partir de uma visão abrangente da mesma.

- Contribuir para a formação de cidadãos capazes de formular e executar propostas válidas, coerentes e orientadas a uma melhoria da sociedade humana tomada como conjunto.

- Contribuir para a formação de cidadãos que sejam capazes de compreender a vasta potencialidade que existe no interior de cada ser humano e, a partir daí, aplicá-la em benefício dos altos ideais que a Humanidade tem desenvolvido através dos tempos.

- Contribuir para a preparação de cidadãos dotados de compreensão holística, capazes de perceberem o Universo, o Planeta e a Natureza, não como mundos estranhos e perigosos, e sim como uma Unidade da qual não tecemos a rede da Vida. Apenas somos fios dEla.

- Capacitar cidadãos para desenvolver seus Projetos de Vida Pessoais, harmonizando a biodiversidade própria de cada ser humano com aquela Unidade.

\section{* Conteúdo programático}

A idéia básica é desenvolver a capacidade de pensar, sentir e agir num marco referencial bastante diferente do utilizado tradicionalmente no meio acadêmico.

Trata-se de um enfoque transdisciplinar, orientado para a formação de pessoas capazes de liderar uma nova sociedade centrada na Vida.

\section{* Estrutura básica do Projeto}

- Módulo I (24 horas)

- Abordagem Holística (12 horas).

- A Redescoberta das Potencialidas Internas do Ser Humano (12 horas).

- Módulo II (24 horas)

- O Projeto de Vida Pessoal (12 horas).

- O Significado e o Sentido da Vida Humana (12 horas).

- Módulo III (Duração indefinida)

- O Laboratório das Novas Idéias.

\section{* Público-alvo:}


Revista Eletrônica de Ciência Administrativa (RECADM) - ISSN 1677-7387 Faculdade Cenecista de Campo Largo - Coordenação do Curso de Administração v. 3, n. 2, nov./2004 - http://revistas.facecla.com.br/index.php/recadm/

- Cursos de Extensão (Presenciais e a Distância): Profissionais de todas as árias do conhecimento, assim como estudantes e pessoas não formadas, mas dotadas de capacidade de liderança.

- Ciclo de Conferência: Para todo público. 


\section{BIBLIOGRAFIA}

ASSAGIOLI R. The act of will. Nova lorque: Penguim, 1971.

BOFF L. Espiritualidade: um caminho de transformação. Rio de Janeiro: Sextante, 2001.

BONILLA J. A. Resposta à Crise: Qualidade Total Autêntica em Bens e Serviços. São Paulo: Makron Books, 1993.

CAPRA F. O Ponto de Mutação. São Paulo: Cultrix, 1982.

DILLARD A. For the Time Being. Nova lorque: Vintage, 1999.

GUITTON J., G. BOGDANOV e I. BOGDANOV. Deus e a Ciência: em direção ao metarrealismo. Rio de Janeiro: Nova Fronteira, 1992.

HAWLEY J. Redespertar espiritual no trabalho. Rio de Janeiro: Record, 1995.

RIBEIRO D. Crisis estuctural de la universidad latinoamericana. Montevideu: Universidad de la República, 1969.

SABETTI S. O Princípio da Totalidade: uma análise do processo da energia vital. São Paulo: Summus, 1991.

TALBOT M. O Universo Holográfico. São Paulo: Best-Seller. 1991.

UNESCO. Declaración Mundial sobre Educación Superior en el Siglo XXI: Visión y Acción. Conferencia Mundial sobre Educación Superior, Paris, outubro 1998, 10 p. Disponível em <http://www.habitantes.elsitio,com/burente/conferencia> Acesso em 15.jul.2001.

WOLMAN R. Inteligência espiritual. São Paulo: Ediouro, 2001.

ZOHAR D. e I. MARSHALL. Inteligência Espiritual. Rio de Janeiro: Record, 2000. 